\title{
LA CONFORMACIÓN DEL SITIO ARQUEOLÓGICO DE HUELVA. PROCESOS NATURALES Y ACTIVIDAD HUMANA
}

\author{
THE FORMATION OF THE ARCHAEOLOGICAL SITE OF HUELVA. \\ NATURAL PROCESSES AND HUMAN ACTIVITY
}

\author{
FRANCISCO GÓMEZ TOSCANO* \\ JOSÉ M. BELTRÁN PINZÓN* \\ JAVIER RASTROJO LUNAR*
}

\begin{abstract}
Resumen: Como alternativa a las interpretaciones realizadas en décadas anteriores, se explica desde planteamientos geoarqueológicos la conformación del sitio arqueológico de Huelva, resaltando la interrelación de los procesos naturales y antrópicos a lo largo del tiempo. Como ejemplo se incide en la explicación del relleno de una de las vaguadas existentes entre los cabezos de San Pedro y del Cementerio Viejo, en la conformación de la estratigrafia posdeposicional del Área Tres del Cabezo de la Esperanza, y en la localización y conformación del reborde de la llanura mareal bajo la actual calle Méndez Núñez en una fase de la Protohistoria. Palabras clave: Geoarqueología Yacimiento arqueológico Huelva España
\end{abstract}

\section{GEOARQUEOLOGÍA E INTERPRETACIÓN ARQUEOLÓGICA}

En el desarrollo científico de la Arqueología más reciente, es bien conocida la necesidad de que el investigador establezca un método y unas técnicas que combinadas trabajen de acuerdo para explicar, desde la

* Universidad de Huelva. Este trabajo se enmarca en el proyecto de investigación Análisis de la implantación y evolución del fenómeno urbano en el Suroeste peninsular: Arqueología Urbana en la Ciudad de Huelva, Ministerio de Ciencia y Tecnología HUM 2004-01790.
Abstract: As a geoarchaeological alternative to last decades explications of the archaeological excavations carried out in the site of Huelva, the interconnections of natural and antropogenic processes are used to explicate the archaeological data. As working examples, the infill of $\mathrm{Ca}-$ bezo de San Pedro and Cabezo del Cementerio Viejo small palaeovalley, a postdeposicional stratigrafy in Cabezo de la Esperanza Área Tres, and the protohistorical tidal flat archaeological data under Méndez Núñez street are hereby presented.

Key words: Geoarchaeology Archaeological Site Huelva Spain

cientificidad, el resultado de cualquier tipo de estudio histórico. Pero, también, fruto de la experiencia, deberá contar con algo más que aquel endeble conocimiento que adquirimos con las lecciones de nuestro profesor de Metodología o leímos apresuradamente en el manual al uso correspondiente en los años de nuestra licenciatura, a pesar de que las hayamos puesto en práctica durante muchos años después, siempre desde de la forma más estricta posible y de acuerdo con la variabilidad de cada actuación arqueológica que determinaba los objetivos a cumplir. Todos sabemos que las últimas décadas han sido decisivas para alcanzar un método interpretativo en Arqueología que satisfaga plenamente nuestra curiosidad científica y que, de la misma 
forma, permita que nuestros colegas puedan entender y reconstruir aséptica y fácilmente nuestro trabajo, a partir de las preceptivas memorias y no sólo desde cualquier otro tipo de publicación donde sólo se exponga la interpretación que de forma unilateral hacemos de nuestras actividades, en especial en lo que se refiere al desarrollo de los trabajos de campo que generan las evidencias empíricas y, se quiera o no, tienen que ser los cimientos que sostengan nuestras conclusiones histórico-arqueológicas.

Precisamente en relación con el trabajo de campo, la tradición investigadora desarrolló durante la mayor parte de la segunda mitad del siglo XX el sistema de excavar sistemáticamente mediante la extracción manual de niveles artificiales o aleatorios horizontales, con los que el conjunto de materiales documentados sucesivamente a medida que se profundizaba en el suelo, servía para explicar de arriba a abajo, o de abajo a arriba una vez completada la actuación, la evolución en el tiempo de la sociedad que los había creado, usado y desdeñado una vez rotos o inservibles, siendo en ellos, como en un libro leído desde el capítulo final al de la introducción, donde se fundamentaban los diferentes episodios histórico-arqueológicos. Con ello, de acuerdo con los antecedentes de la estratigrafía geológica, de la superposición en el espacio de los artefactos localizados, entendiendo que los más profundos tenían que ser siempre más antiguos que los más superficiales, se podía obtener, sólo con ellos, una clasificación histórico-cronológica como base de interpretación histórica.

Con esta técnica, sin cualquier reflexión considerada inconveniente y sus resultados no válidos por muchos arqueólogos en los inicios del siglo XXI, se realizaron las excavaciones llevadas acabo en Huelva incluso hasta los años finales de la década de los noventa, y a partir de ella se explicó la evolución en el tiempo de la ciudad, desde la primitiva existencia del puerto protohistórico hasta la nueva capital de provincia creada en el siglo XIX, pues, sólo hasta muy recientemente, con la nueva generación de arqueólogos profesionales involucrados en las excavaciones de urgencia o preventivas, no se ha generalizado el uso del concepto de Unidad Estratigráfica, que en un principio, aunque no tiene ningún valor interpretativo, sino que, siguiendo a E.C. Harris (1989), se trata de la más pequeña división que puede reconocerse en un yacimiento arqueológico, física o de otro tipo y, por lo tanto, una interpretación estrictamente arqueológica y no basada en presupuestos tomados de la geología, bien sea de los restos de un edificio, un pozo excavado en el subsuelo, los de un pavimento de cualquier tipo o técnica constructiva, una zona pisada que sirvió de camino de acceso o de entrada a una cabaña, un horno, o el área de vertido de ese horno, que en realidad ha significado contar con un punto de partida lógico y fácilmente comprensible, el cual antes era realmente insospechado y que todavía, como hemos dicho, encuentra reticencia entre algunos arqueólogos experimentados habituados a trabajar con el método aleatorio.

No obstante, desde un punto de vista geomorfológico y como explicación actual para nosotros mucho más comprensiva, contamos con el concepto descriptivo -cualitativo- de cada unidad estratigráfica establecido por K. W. Butzer (1982) como el resultado positivo de un proceso erosivo-sedimentario, el cual implica que en cualquier estratigrafía arqueológica que realicemos existirán unidades positivas que, independientemente de corresponderle una clara génesis específica, podemos diferenciar y definir precisamente por su color, composición, restos materiales que incorporan, estructura y/o simplemente aspecto, que diferencia a cada una de ellas del resto de las de su entorno más inmediato, tanto en cuanto puede presentar cotas absolutas y una amplitud mensurable en el espacio.

Pero, también sabemos, o debiéramos saber, que ello implica que al mismo tiempo y en ese mismo espacio, además, pudieron existir en otro momento otras unidades negativas, también formadas a partir de un proceso específico que se deberá intentar descubrir y definir, que ya desaparecieron y que ahora únicamente podemos reconstruir a partir de la hipótesis, pero que sin duda se encontraban allí en un momento dado y estuvieron incluidas en el mismo espacio que ahora está ocupado por una o varias unidades positivas de génesis posterior, cuya duración en el tiempo podría incluir días, años o varios siglos.

¿Cómo debemos explicar, pues, una estratigrafía arqueológica, y cómo interpretarla históricamente? ¿Será únicamente la sucesión de materiales arqueológicos tales como la cerámica, estudiados como fósiles-guía cada uno de ellos, contemplados desde una tipología específica establecida por nuestros maestros hace cuarenta años o, simplemente, como puede interpretarse desde la lectura de uno o varios artículos publicados donde aparezcan materiales arqueológicos semejantes, aunque hayan sido localizados en contextos que pueden estar alejados del nuestro varios miles de kilómetros y corresponder a ejemplos que nada tengan que ver con el que estudiamos?

En relación con lo anterior, todos nos acordamos de esas listas interminables de paralelos reiterativos que para cada pieza aparecían recurrentemente en los trabajos publicados durante los años setenta, los ochenta y posteriores, con cronologías aparentemente similares, 
largas e imprecisas y, en la mayor parte de los casos, muy diferentes unas de otras, las cuales daban lugar a que de forma extraña e incomprensible a algunas piezas, o a unos tipos cerámicos sincrónicos específicos, se otorgasen siglos de existencia cuando debían responder, como mucho, al uso de ellos por una o dos generaciones, en realidad un espacio comprendido entre veinticinco y cincuenta años pongamos por caso.

Hoy sabemos que hace falta algo más. En principio, existen demasiadas variantes físicas comprobadas para que todo yacimiento arqueológico sea tratado como ejemplo único e irrepetible, ya que la síntesis de la ocupación humana y la evolución de los agentes naturales, en conjunto, han podido determinar que los restos del pasado se presenten a los arqueólogos de forma muy diferente de cómo se depositaron en la Antigüedad, por lo que la sucesión de los sedimentos establecida en un mismo yacimiento no tiene que ser la misma en cada lugar excavado, incluso cuando estén situados a unos pocos metros los unos de los otros. Tampoco, cada uno de los componentes de cada conjunto arqueológico actual tuvo que estar presente en el momento de su creación, sino que a ese conjunto pudieron añadirse otros elementos con el paso de los años, en este caso como efecto de la sucesión en el tiempo de diversos procesos, generalmente naturales, pero también de índole o génesis antrópica.

Desde este punto de vista, en la explicación de cómo se presentan los restos excavados en cada sitio, deberá estar ésta precedida por el conocimiento del medio natural al menos a escala general, valorando la posible incidencia de los agentes morfológicos naturales $\mathrm{y}$, fundamentalmente, de la potencial capacidad transformadora del Hombre en cada momento de la evolución humana, pues esta capacidad ha podido repercutir con mayor o menor incidencia en el resultado particular de un paisaje específico a lo largo de los siglos en un mismo medio físico.

Sin embargo, no debe creerse que estemos hablando únicamente desde un principio de índole tafonómica que debe entenderse en momentos previos a la movilización de los objetos, donde la dispersión de los mismos en cada yacimiento, irrepetible en cada caso en particular, ya sea en el estudio de éste específicamente, a cualquiera de los niveles de análisis micro, medio o macro, pueda mensurarse fácilmente sin aplicar los métodos geoarqueológicos necesarios, que no implica sea esa una tarea que deba ser realizada exclusivamente por geógrafos o por geólogos, como se ha intentado imponer en algún caso reciente, aunque creemos que tampoco es una tarea que pueda llevarse a cabo exclusivamente por arqueólogos que no conozcan al menos los principios goarqueológicos establecidos por K. W.
Butzer en la década de los setenta y ochenta. Sin duda, la conclusión que aquí debe deducirse es que a lo largo del tiempo la Arqueología, a pesar de ser una ciencia empírica fundamentalmente histórica, puede y debe incluir entre sus métodos aquellos que pudieron ser desarrollados en el seno de otras especialidades que nada tenga que ver con la Historia.

\section{EL SITIO ARQUEOLÓGICO DE HUELVA Y SU FORMACIÓN A TRAVÉS DEL TIEMPO}

Hace unos seis mil años, se completó un proceso generalizado de calentamiento experimentado a escala global, durante el cual debemos resaltar que tuvo lugar la desaparición de una parte importante del agua en estado sólido existente en los casquetes polares de nuestro planeta. También, como primer resultado de ese proceso continuado y progresivo, dado que el volumen de agua existente en la Tierra siempre es el mismo, a lo largo de varios siglos ese aumento de agua líquida en los océanos determinó a escala global la subida de la línea costera hasta un límite aproximado al que ahora conocemos (Ojeda 1997: 124; Rodríguez y otros 1997). En el caso local de la ría de Huelva, con la última etapa de subida del mar, incluida en el proceso denominado Máximo Transgresivo Flandriense, la orilla del mar alcanzó el reborde de las alturas que conocemos en los últimos siglos como los cabezos, situándose a su pie en una unidad labrada por las olas en la línea de marea, con la forma de un acantilado de aproximadamente 50 metros de altura, que se adentraba hacia el interior continental por medio de la plataforma de los cabezos que formaba una parte extrema de la orografía previa a la transgresión del mar.

La evolución natural en el período geológico más reciente que conocemos como Holoceno, comenzaría a incidir en la morfología del entorno de esos cabezos y de los acantilados recién formados cuando fueron cortados por las olas, empezando a modelarse la zona más meridional de los mismos como un paisaje muy específico influenciado cada vez más por la presencia del hombre que, tal vez desde el IV Milenio a.C., se asentó en el lugar ocupado ahora por la ciudad de Huelva, siendo favorecida esa influencia por la escasa consistencia de los materiales arcillosos del sustrato amarillento del período Terciario que conforman la componente más reciente de la zona, la cual también puede aparecer sobremontada por procesos relacionados con diferentes grados de resistencia a la erosión en algunas superficies aisladas por unidades sedimentarias posteriores del período Cuaternario, de color rojizo, en este caso con un gran aporte de grava y arena 
de origen fluvial como componente. Como se ha dicho, en ese proceso de subida del mar se labró el mencionado acantilado que, por ello, suele denominarse acantilado flandriense, en relación con las costas atlánticas meridionales de la Península Ibérica. Con el tiempo, los procesos naturales incidieron sobre el material blando de esas formaciones locales, en especial a través de la erosión del agua de lluvia en los períodos húmedos y su alternancia con una casi total sequía en los meses de verano que corresponde al régimen mediterráneo del clima meridional de esta zona de la Península.

Con ello, a lo largo del tiempo, la circulación superficial del agua arrastró a su paso los materiales arcillosos disueltos por la lluvia, así como fracciones de grava y arena depositadas en las zonas más altas de los paquetes de sedimentos como resultado de la morfología desarrollada en el período Cuaternario, transportándolos por gravedad a zonas más bajas donde, al perder competencia la circulación hídrica, quedarían depositados como resultado de esa escorrentía superficial. Como es lógico, dado que la fuerza erosiva de la corriente superficial disminuiría progresivamente al ritmo de las precipitaciones en cada momento, la deposición de los arrastres también sería gradual, quedando parados primero los materiales más pesados y superponiéndose a ellos los más ligeros, incluso como limpios paquetes de arcilla amarillenta, o más o menos rojiza dependiendo del material de partida, al espesarse su condición de barro por una completa evaporación del agua que los movilizó, tal como se han definido la mayor parte de los paquetes sedimentarios, los estratos así delimitados en la excavaciones arqueológicas.

A partir de la presencia del Hombre, junto con estos paquetes de sedimentos de constitución heterogénea, también se movilizarían cascotes y basuras existentes por cualquier proceso en la superficie del hábitat, de génesis tanto natural como antrópica, que serían desplazados sucesivamente por la alternancia de los períodos de lluvia, pasando desde el lugar en que en su día fueron despreciados por el hombre a otros diferentes, siempre moviéndose hacia abajo de la pendiente por gravedad, debido a la morfología de la circulación superficial, lo que conocemos en Arqueología como movilización en un proceso postdeposicional. Resulta claro pues, que a medida que se fueron incrementando las técnicas constructivas transformadoras del medio físico y los procesos de urbanización de la ciudad, por las principales vías, primero pisadas y después empedradas o enlosadas, la competencia de las arroyadas se incrementó y con ello el caudal y el poder erosivo-sedimentario de la circulación superficial con la escorrentía del agua de lluvia en períodos de fuertes precipitaciones.
De esa manera, vemos que la acumulación individual de los sedimentos humanos en el hábitat onubense que descubrimos con las estratigrafías arqueológicas, se originó, cada una de ellas, como resultado de procesos naturales, la circulación sub y superficial del agua de lluvia y, en general, por el incremento de la actividad humana, una morfología que por su importancia formativa ya hemos comentado en otro lugar (Gómez y Campos 2001). Teniendo en cuenta la incidencia de la componente geológica de los cabezos, al tratarse de procesos correlativos, la erosión, el transporte y la sedimentación de los residuos humanos se sucederían en el tiempo, desde el momento de su deposición, cuando quiera que fuese, hasta la actualidad, que es cuando serán descubiertos en las excavaciones, formando y conformando sucesivamente estratigrafías únicas e irrepetibles, tanto por los materiales en sí mismos como por su específica distribución en un espacio determinado.

En ese proceso generalizado de formación y conformación del espacio habitado debemos tener en cuenta, como ya se ha dicho, el aumento de la capacidad técnica de la sociedad de cada momento (Campos y Gómez 1997). Si para la Antigüedad no contamos con datos específicos, de acuerdo con los relatos escritos conservados, en los últimos siglos se hicieron importantes obras que significaron un cambio radical del paisaje de la ciudad en las zonas llanas y en sus cabezos, complicando el resultado de la evolución morfológica. Con la modernidad, la pequeña villa de Huelva se transformaría en la ciudad industrial del siglo XIX, substituida mediante un desarrollo urbanístico desmedido en la ciudad del siglo XX (Díaz Zamorano 1999). En esos dos siglos inicialmente se desmontaron cabezos para ganar terreno a la ría y marismas (Figura 2), y luego, sin discriminación, se derribaron edificios, en algunos casos centenarios, para acomodar otros proyectos arquitectónicos y urbanísticos que por ser actuales no serían mejores, dando lugar a la radical transformación del casco antiguo y de su entorno, el cual sólo se ha conservado en la planta de su callejero y no en su aspecto exterior (Figura 1), una información imprescindible a la hora de explicar la ocupación del espacio donde se desarrolló la ciudad a través del tiempo.

\section{ALGUNOS MODELOS DE REINTERPRETACIÓN GEOARQUEOLÓGICA}

Las primeras excavaciones llevadas a cabo en Huelva comenzaron en los cabezos (Gómez y Campos 2001), empezándose en la década de los años sesenta a trabajar en los de la Esperanza y en el de La Joya, orientadas precisamente a documentar los posibles restos de 


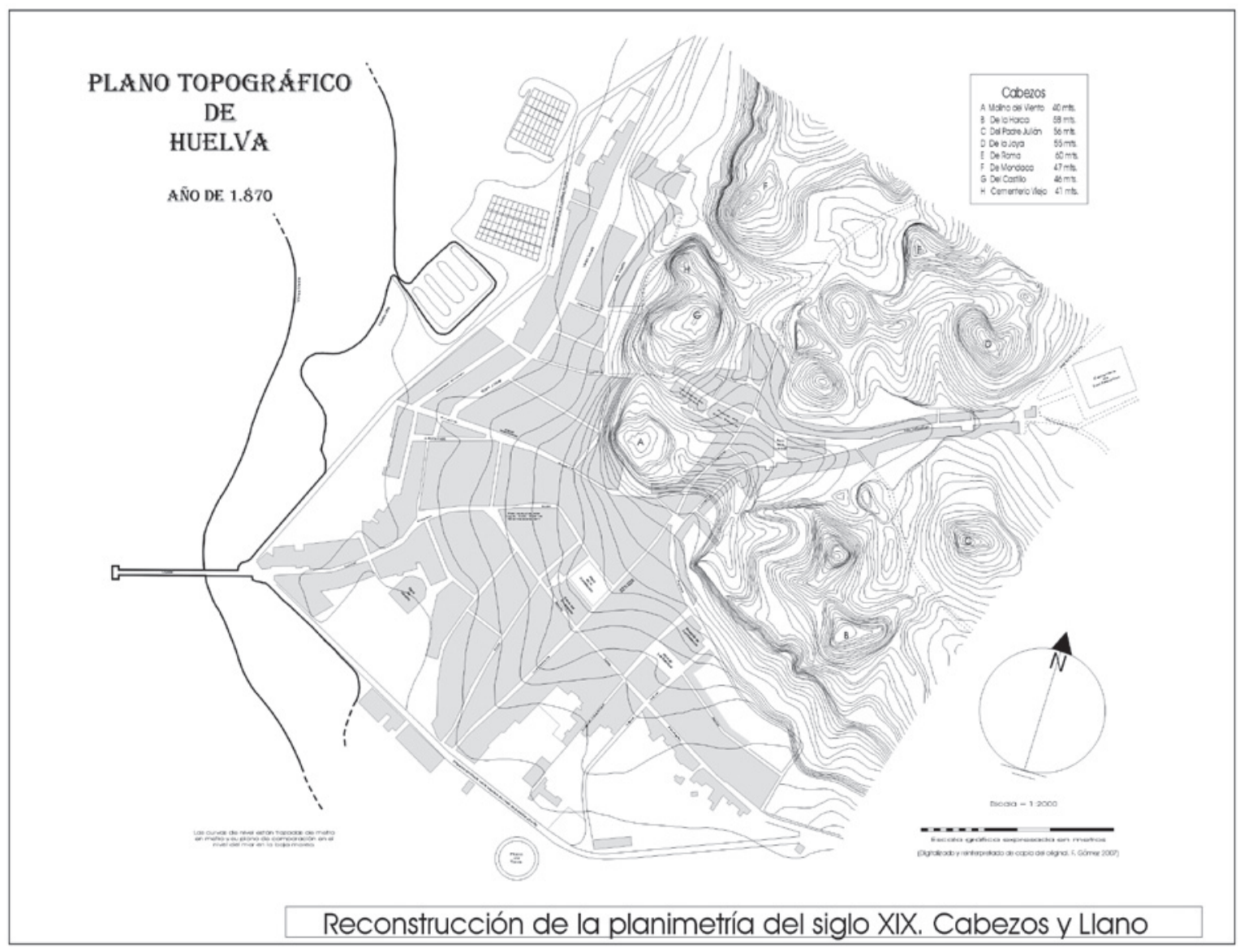

Figura 1. Planimetría modificada tomando como base un plano conservado en Huelva de 1870 , mostrando su esquema urbano junto con los cabezos existentes.

una mítica ciudad tartésica que allí debía encontrarse (Garrido 1968; Garrido y Orta 1975; 1978). Durante los años 1968 y 1969 se descubrió la primera estratigrafía importante en el Cabezo de San Pedro (Blázquez y otros 1970) que, como veremos a continuación, mostraba por primera vez la historia arqueológica de Huelva; al menos en sus diferentes niveles quedan restos materiales prehistóricos, protohistóricos e históricos. En la década siguiente, en el mismo cabezo y sus laderas, se llevaron a cabo diferentes trabajos arqueológicos (Belén y otros 1983; Amo y Belén 1981) y, especialmente en la cima (Blázquez y otros 1979; Ruiz Mata y otros 1981). Aunque no vamos a analizar aquí ninguno de esos trabajos en particular, lo que quedó siempre de manifiesto en todos ellos es la tremenda incidencia de los procesos de evolución de la cima y de sus laderas que, en conjunto, mostraron claramente que los materiales arqueológicos incluidos en los paquetes sedimentarios que conocemos como estratos arqueológicos o unidades arqueológicas, fueron movilizados e incluidos en esos paquetes como resultado de procesos erosivo-sedimentarios de génesis o conformación heterogénea. En cuanto a las laderas, con mayor o menor pendiente, pero debido a la gravedad y a los procesos naturales especialmente, se originó el desplazamiento de grandes paquetes sedimentarios que también se incluyeron en estratigrafías de génesis erosiva. Con el masivo hallazgo de restos antiguos en las laderas, sin duda procedentes de las superficies localizadas a mayor altura, se interpretó que éstas fueron las habitadas exclusivamente en detrimento de las cimas, como parece lógico a partir de la apariencia de las estratigrafías realizadas en el Cabezo de la Esperanza (Fernández 1990).

En la década de los años setenta, se localizaron los primeros restos de la ocupación romana y prerromana de la ciudad (Gómez y Campos 2001), debido a la excavación del subsuelo para cimentar los nuevos edificios que destruyeron casi completamente la extensión urbanística de la ciudad que se había conservado hasta 

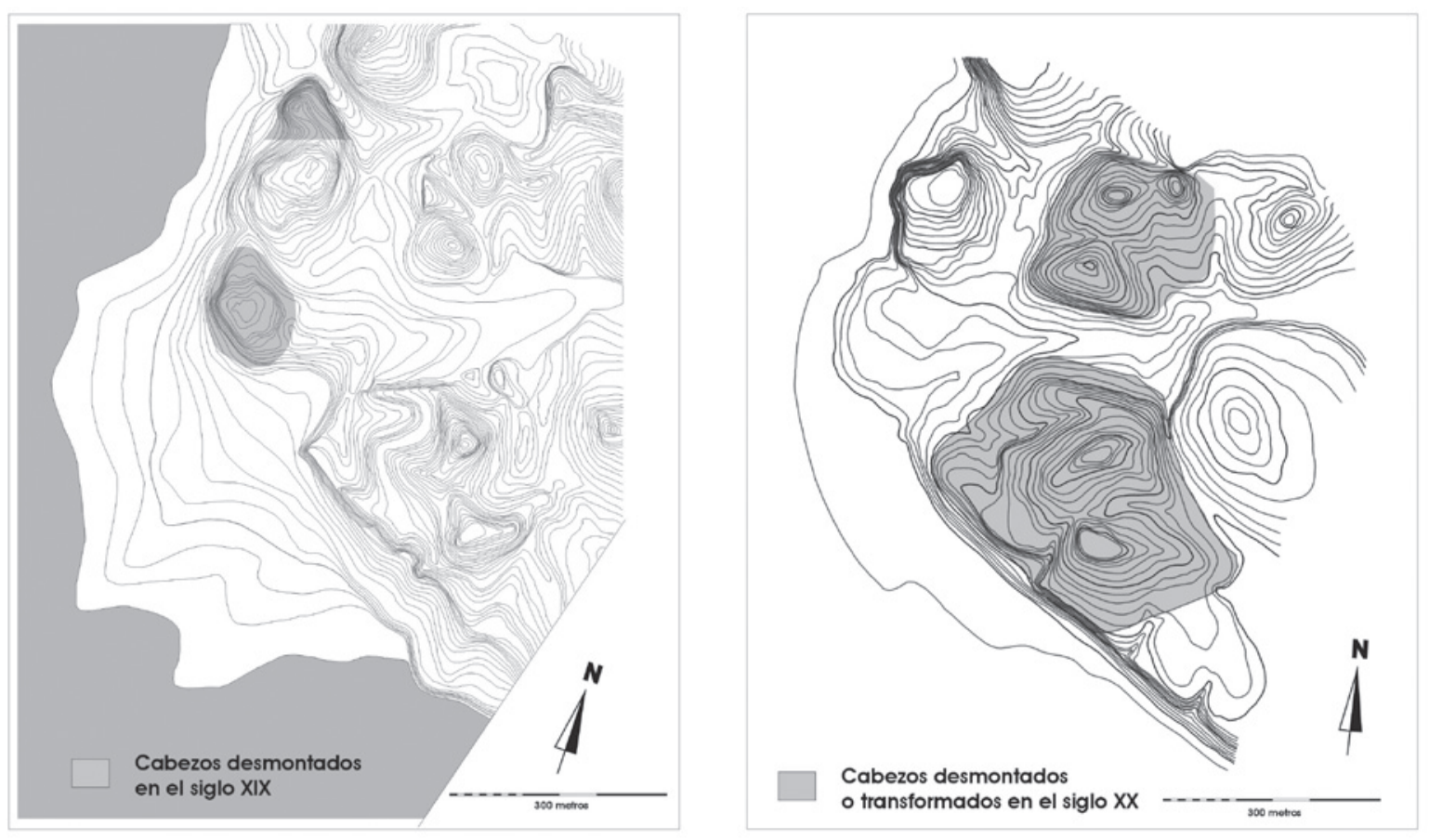

Figura 2. Morfología de los cabezos basada en diferentes planos conservados, mostrando los cabezos desmontados durante los siglo XIX y XX.

el siglo XX. En este caso, los restos arqueológicos se encontraban ocultos bajo varios metros de sedimentos procedentes de las zonas altas, que muestran aquí que en las zonas bajas la génesis de los procesos de formación fue casi exclusivamente de acumulación sedimentaria, mientras que como se ha visto en las alturas predominaron los procesos erosivos.

En el conjunto del asentamiento, tanto en las laderas de los cabezos como en esas zonas bajas, donde se concentraban los principales canales o ejes de arroyada procedentes de las alturas (Figura 3), los procesos erosivo-sedimentarios se alternaron a escala anual. Si en la temporada invernal el agua superficial erosionaba el trazado de esos ejes, denominados en Huelva vulgarmente el arroyo, desplazando los materiales en ellos incluidos a favor de la pendiente hacia las marismas, durante los amplios estiajes del clima mediterráneo de la zona, a esos arroyos prácticamente secos se arrojaban las basuras y cualquier otro detrito generado por la ocupación humana del momento, donde permanecían hasta que se reiniciaba el proceso a partir de las primeras lluvias. Por lo tanto, las estratigrafías postdeposicionales que existían en esos ejes o en su entorno más inmediato pudieron ser arrasadas completamente o cortados sus rebordes y vueltos a rellenar por unidades sedimentarias nuevas y diferentes, como se observa claramente en algunas estratigrafías excavadas en las décadas de los ochenta y noventa, según un ejemplo que veremos más adelante. Con ello, muchos de los materiales que hoy se encuentran en el borde de la antigua marisma, en realidad pudieren ser desechados por primera vez en las zonas más altas del hábitat, incluso en el Cabezo de San Pedro ${ }^{1}$.

\subsection{Cabezo de San Pedro. Un ejemplo de relleno de vaguada con predominio de erosión natural}

Aislado como resultado del desmonte del Cabezo del Molino de Viento y del Cementerio Viejo en los siglos XVIII-XIX, el Cabezo de San Pedro presentaba

1. Siempre ha resultado extraño que no se localizaran cerámicas griegas arcaicas del siglo VI a.C. en los niveles correspondientes del Cabezo de San Pedro o en los de La Esperanza, y en cambio son tan frecuentes en el hábitat de las zonas bajas, un hecho que podría indicar que, por cualquier razón, esos niveles desaparecieron de las alturas en las escasas zonas excavadas y se incorporaron a los procesos naturales de arroyada generalizados, habiendo sido localizados tan sólo en las excavaciones realizadas en las zonas bajas más cercanas a las marismas, tanto en suelos de ocupación como en paquetes sedimentarios que los colmataban. 


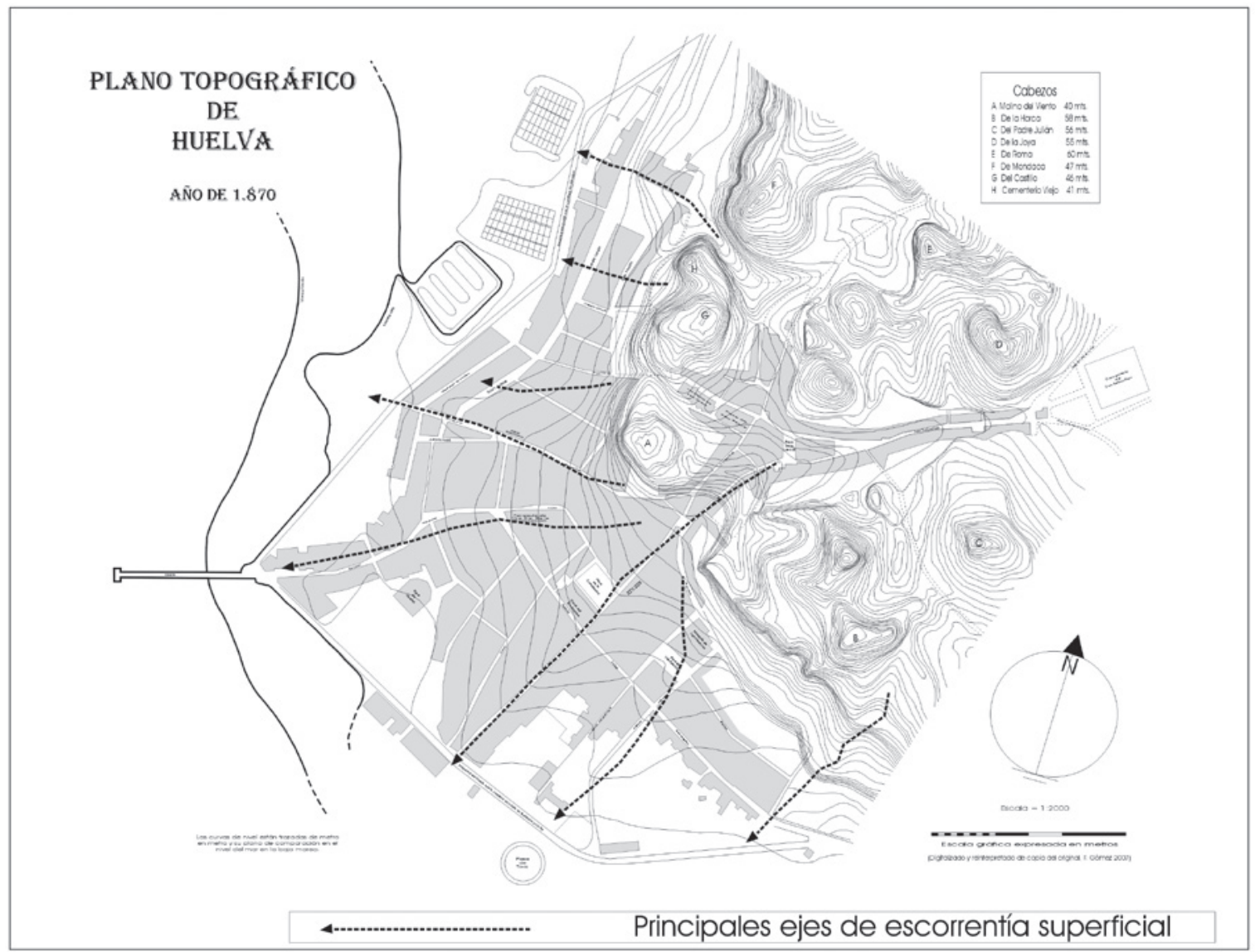

Figura 3. Principales ejes de arroyada y una alternativa de la línea de influencia mareal.

una morfología difícilmente reconocible en estos momentos, a no ser que recurramos a la topografía que podemos comparar con planos de finales del siglo XIX y mediados del XX (Figuras 1, 2, y 5). En los años finales de la década de los sesenta del siglo XX se realizó la limpieza y peinado a mano de la ladera noroeste para evitar peligrosos derrumbes como los que se habían producidos en los años cincuenta en otras zonas del cabezo. Durante los trabajo de limpieza y cortado de la ladera se localizaron múltiples estratos de diferente color y aspecto heterogéneo en general, que conformaban una estratigrafía arqueológica comprendida entre los siglos finales del II Milenio a.C. y la actualidad, la cual mostraba la historia completa de la ocupación del sitio durante unos tres mil años (Blázquez y otros 1970), que de forma extraña no suele ser comentada por los autores más recientes que han trabajado en Huelva, por lo que hemos tenido que revisarla para revindicar su importancia histórico-arqueológica (Gómez y Campos e.p.).
Como resultado del cortado vertical que dejó a la vista un amplio espacio prácticamente vertical, desde la estratigrafía entonces interpretada (Figura 5), puede explicarse la morfología del hábitat situado en la cima del cabezo. En primer lugar, estratos de diferente grosor y características quedaron depositados en la vaguada existente entre el de San Pedro y el del Cementerio Viejo, habiéndose observado en esa estratigrafía. Esos estratos o depósitos heterogéneos se generaron en la cima del primero y debieron también tapizar en algún momento la superficie del segundo por ser de menor altura, una situación que es imposible contrastar ahora debido a la desaparición del segundo como se ha comentado. Aunque en algunos casos se documentaron zonas en los niveles protohistóricos 5 a y 5 b (Figura 5) que pudieran interpretarse como los restos de alguna cabaña construida en la ladera, la mayor parte de los depósitos de detritos de los Niveles históricos fueron el resultado de procesos naturales que bien erosionaron la 

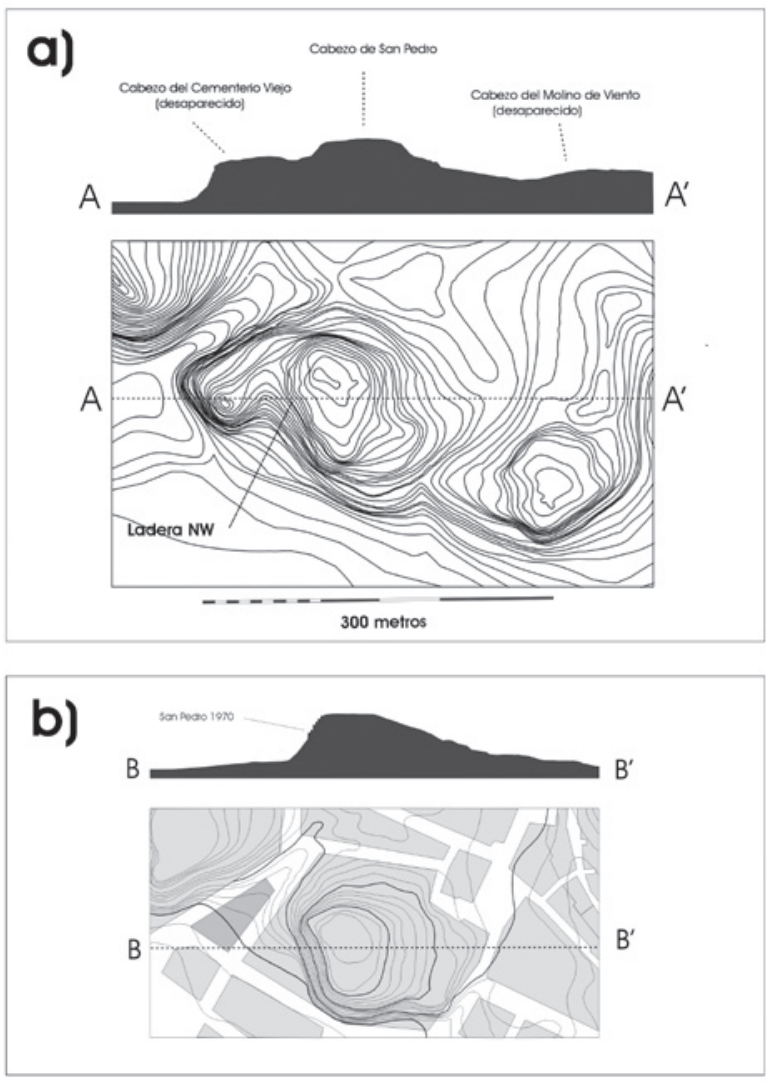

Figura 4. Morfología del Cabezo de San Pedro. A) Interpretación de la situación previa a 1870. B) Interpretación de la situación en década de los años setenta del siglo XX.

cima del cabezo, principalmente con procesos de arroyada que a través de la circulación hídrica natural movilizaron arcilla y finos junto con basura menuda, bien fueron desplazados desde las alturas en procesos de génesis antrópica concretos, para allanar espacios donde construir o reconstruir el hábitat a través de esos tres mil años de ocupación. También podría ser el caso natural conocido en la zona sur del cabezo durante los años cincuenta, que desplazó una parte de reborde por solifluxión y causó la muerte de algunos vecinos que dormían en inmuebles construidos demasiado cerca del cabezo, cuya huella hasta ahora ha permanecido visible desde la calle Aragón.

Con ello, la parte que quedó visible de la ocupación de la cima del Cabezo de San Pedro a través de los últimos tres milenios (Blázquez y otros 1970; Gómez y Campos e.p.), según puede apreciarse en la Figura 5, representa la más amplia secuencia documentada en el sitio arqueológico, aunque debemos resaltar la ocupación más antigua situada en los Niveles 6 y $5 a$, que no había podido ser comprobada en ninguno de los trabajos realizados con posterioridad ${ }^{2}$. Debe destacarse también que esa sucesión estratigráfica no pudo constatarse de forma completa en las campañas realizadas en 1977 y 1978 (Blázquez y otros 1979; Ruiz Mata y otros 1981), localizadas en la cima del cabezo sobre el lugar donde se llevó a cabo la limpieza, y donde fue localizado el muro de contención realizado en parte con técnicas fenicias, de acuerdo con la estratigrafía resultante que representamos a su altura relativa con la misma escala, que por la inclinación de la vaguada apareció retranqueada prácticamente en superficie (Figura 5). En esas campañas no llegó a excavarse por debajo de lo que se interpretó como Fase I, una contrariedad que ha dado lugar a que con posterioridad tesis desafortunadas hayan forzado interpretaciones erróneas acerca del inicio de la actividad humana en el sitio de Huelva, siempre con el propósito de negar la existencia de los estratos de la sociedad del Bronce Final prefenicio que indudablemente se asentó en la cima de ese cabezo y en otras zonas de la ciudad (Gómez y Campos e.p.).

De hecho, lo importante del estudio de la conformación del registro arqueológico del Cabezo de San Pedro, es que cada una de las estratigrafías que en él se analicen dependerán de la ocupación humana del espacio en cuestión a través del tiempo y, por ello, de esa incidencia antrópica que tampoco pudo ser ajena a la evolución natural, a la continuada deposición de sedimentos por diferentes procesos y sus resultados, a su erosión por efecto de la propia incidencia natural y de la consiguiente actividad antrópica, que desmontaron unidades naturales o estructuras construidas por las diferentes sociedades que lo habitaron y preservaron, todo ello causado y repetido sin un límite o una consideración que no pueda ser, al menos, estimada o intuida a través de la lectura geoarqueológica de lo conservado como resultado de cada una de ellas. Por todo lo anterior, como se confirmó en otros trabajos realizados tanto en la cima como en sus laderas (Belén y otros 1978; Amo y Belén 1981), nunca encontraremos en el Cabezo de San Pedro, ni en cualquier otra zona del sitio arqueológico de Huelva, la estratigrafía típica y repetitiva que da lugar a que algunos sitios arqueológicos se

2. En los trabajos que se realizan actualmente en la zona denominada Plan Parcial 8, se están excavando cabañas, silos, tumbas y otras estructuras pertenecientes a los IV-I Milenios a.C., con materiales que ya conocíamos en esos Niveles del Cabezo de San Pedro. Agradecemos a las empresas Ánfora, S.L. y Girha, S.C. y a los diferentes directores de esas actuaciones que nos permitan conocer el desarrollo de esas importantes actividades, cuya publicación hará cambiar muchas de los paradigmas vigentes. 


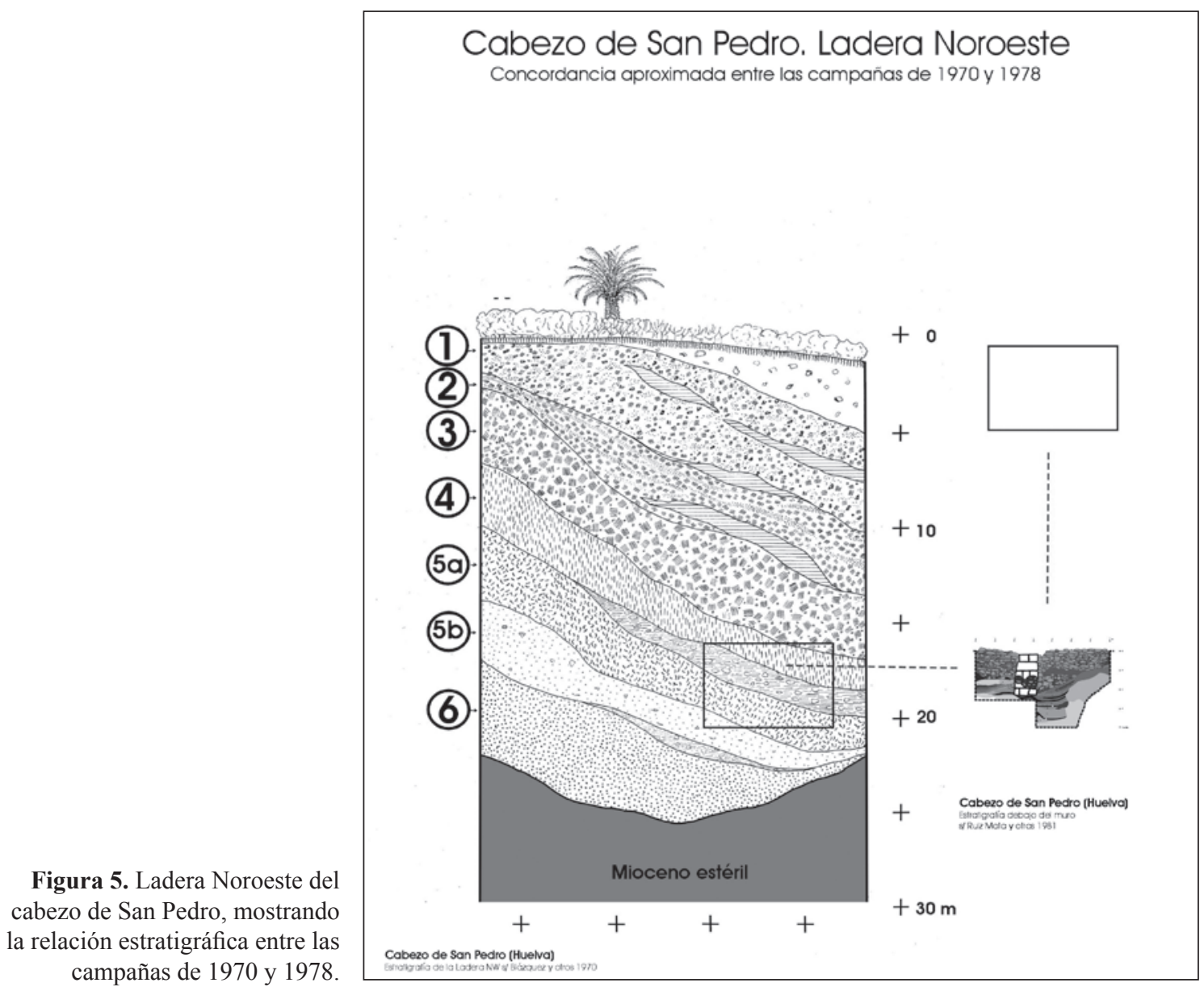

designen con el término tell, al modo de ejemplos excavados en el Próximo Oriente, donde cada período histórico suele situarse a una misma cota.

\subsection{Cabezo de La Esperanza. Área Tres, un modelo de estratigrafía postdeposicional de génesis erosivo-sedimentaria en ladera}

Se trata de una excavación realizada en los primeros años de la década de los setenta del pasado siglo XX, para documentar la superposición de restos cerámicos descubiertos en labores de limpieza que se realizaban en el Cabezo de la Esperanza (Belén y otros 1978: 259-295). En primer lugar, se recogieron cerámicas removidas por una pala mecánica que excavaba unos cimientos a poniente del Cabezo de la Horca y, en una zona que entonces resultaba bastante llana, se plantearon varios sondeos (Figura 6). En esos sondeos estratigráficos se definieron diferentes estratos con materiales que hoy sabemos son de cronología protohistórica diversa, aunque entonces presentaban desigual color y morfología, estando dispuestos con regularidad unos sobre los otros, como si se tratara de una estratigrafía normalizada de las conocidas en cualquier tell típico, aunque los autores reconocen que las estratigrafías observadas eran poco aceptables. En primer lugar el estrato superficial estaba removido por los trabajos de limpieza y, a continuación se documentaron los restos de posibles tumbas muy destruidas, que se relacionaron con una necrópolis de los siglos XVI-XVII, aunque la mayor parte de las cerámicas recuperadas eran de cronología antigua. El resto de los niveles arqueológicos fueron definidos en la Cuadrícula A-1 fundamentalmente porque en ellos no aparecían restos de necrópolis y porque presentaban un color y unas características diferentes. En algunas zonas, los diversos estratos se diferenciaban por la aparición de pasadas de gravas, que se relacionaron lógicamente con lechos de guijarros pertenecientes a arroyadas, y arcillas del sustrato terciario, generalmente limpias y homogéneas a simple vista.

En total, se estudiaron 917 fragmentos cerámicos que incluía 10 bruñidos a mano y 164 a mano no 


\section{Cabezo de la Esperanza (Huelva)}
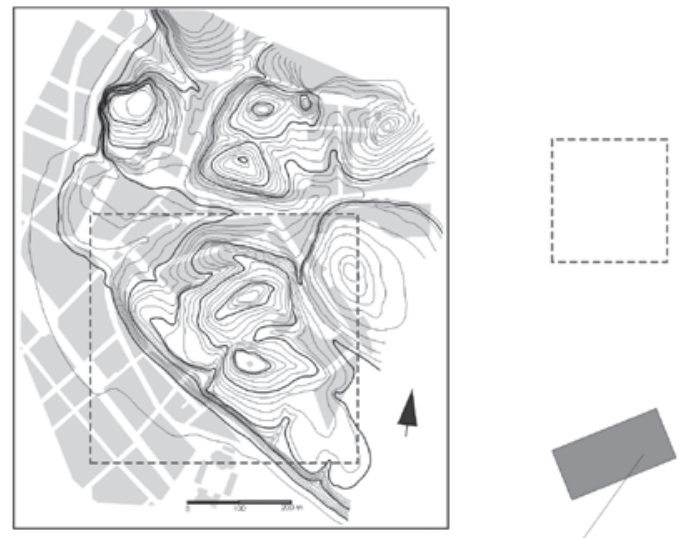

Zona ampliada abajo

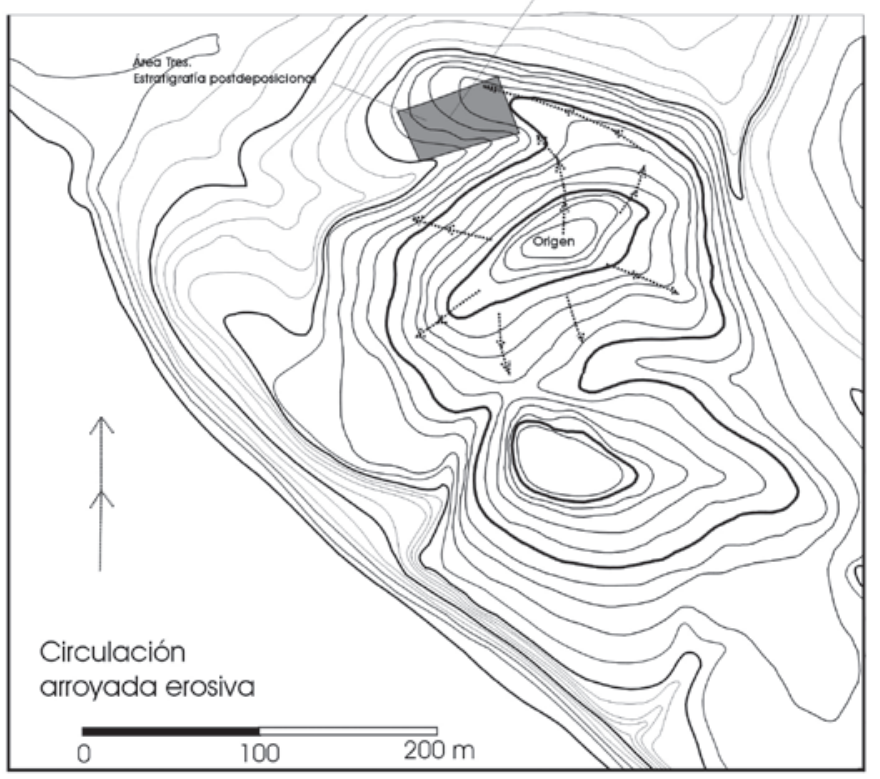

Localización aproximada del Área Tres.
Figura 6. Cabezo de la Esperanza. Interpretación de la evolución de ladera de uno de los ya desaparecidos, donde se localizó la excavación denominada Área Tres. bruñidos, entre los que hemos seleccionado algunos ejemplos ilustrativos pertenecientes a diversos cortes y estratos, que nos parece deben corresponder a un momento sincrónico (Figura 7), y que son la muestra de una de las fases más antiguas de la ocupación de Huelva al final de la Edad del Bronce, en parte sincrónica con el Nivel 6 del Cabezo de San Pedro definido en 1970 (Gómez y Campos e.p.; Gómez e.p.). El resto de los fragmentos corresponde a vasos cerámicos principalmente a torno, que hoy pueden encuadrarse con facilidad en una fase tardía del Período Orientalizante, en especial un fragmento de copa jonia arcaica (Belén y otros 1978: Fig. 143, 8), faltando o siendo prácticamente nulo entre ellos cualquier tipo de cerámica del Bronce Final clásico de las conocidas en el Cabezo de San Pedro en sus fases I y II (Blázquez y otros 1979; Ruiz Mata y otros 1981).

Por tanto, a través del estudio de los materiales publicados de cada estrato y la descripción de los niveles diferenciados en cada corte, parece claro que en este caso la sucesión estratigráfica, como quiera que se presentara, nada tiene que ver con la deposición de elementos de cultura material en momentos históricos independientes como resultado de la ocupación humana, sino que ésta estuvo conformada por capas depositadas en diversos momentos temporales que nada tienen que ver con una misma cronología temporal específica y, por ello, todo el conjunto de paquetes sedimentarios y las cerámicas diacrónicas en ellos incluidas llegaron al 


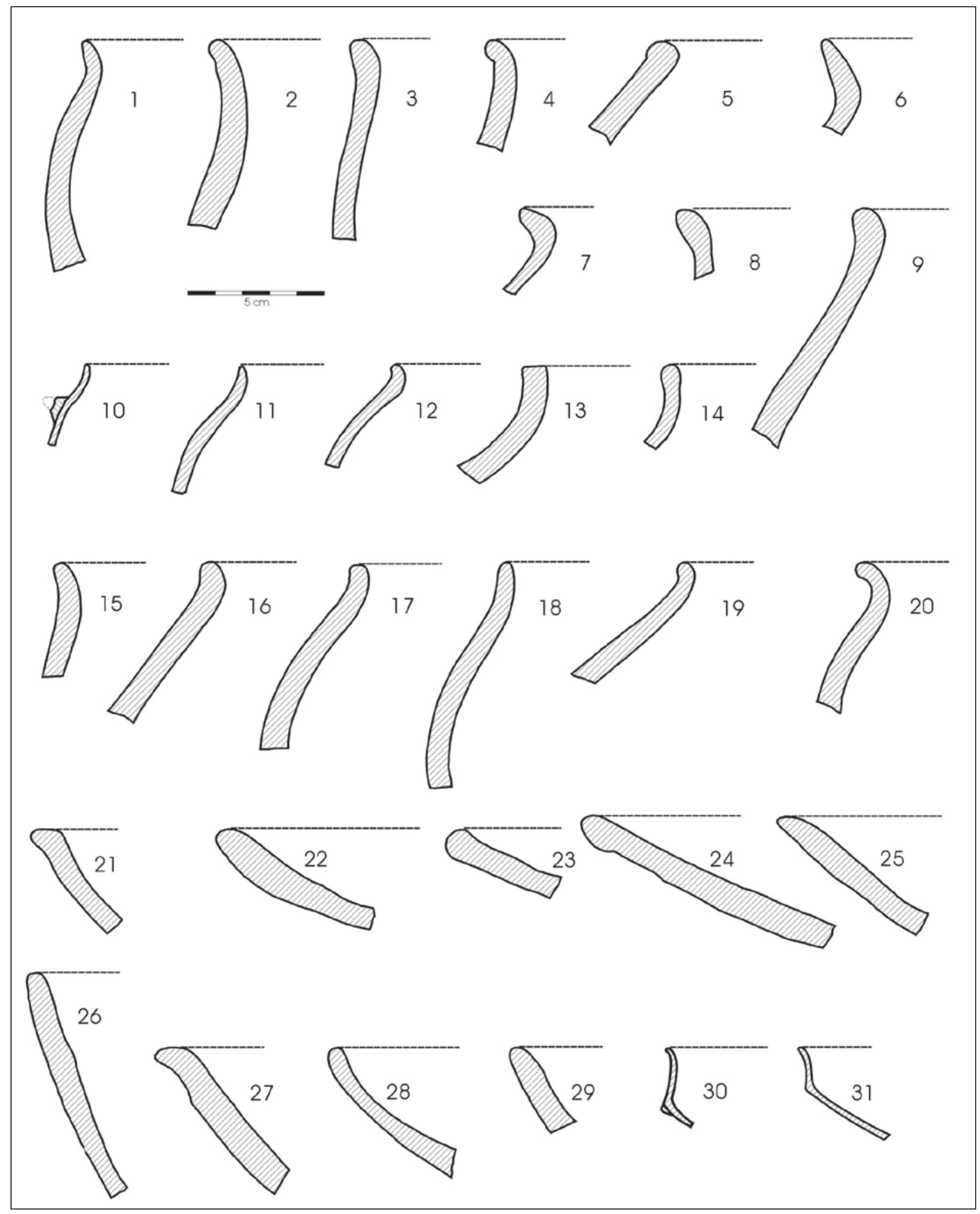

Figura 7. Selección de materiales del Horizonte Formativo documentados en diferentes estratos postdeposicionales de la excavación del Área Tres del Cabezo de la Esperanza, reproducidos de los publicados por Belén y otros, 1978. 
lugar donde fueron localizadas en la excavación en diversos momentos por su desplazamiento gradual desde las zonas más altas del cabezo, donde sí tuvo que existir un riguroso orden de deposición regular y que el desplazamiento natural lógicamente no respetó.

Debemos resaltar que no se trata de restar cualquier crédito a los investigadores que hace casi cuarenta años interpretaron la sucesión estratigráfica como lo hicieron y publicaron, que lógicamente merecen un respeto dado el nivel de conocimientos de esos momentos y los de ahora, sino simplemente que nuestra intención es mostrar una realidad morfológica específica y unas circunstancias que hemos aprendido a explicar mucho después al trabajar con métodos entonces desconocidos, lo cual también deberá ser un claro ejemplo a la hora de interpretar futuras excavaciones que se realicen en los cabezos y en las zonas llanas de Huelva.

\subsection{Calle Méndez Núñez. Modelo de evolución de la línea mareal}

Según un reciente esquema geológico-estratigráfico dado a conocer (González y otros 2004), por encima de fangos de estero típicos de color gris, donde está ausente cualquier resto humano, se depositó un estrato negro o gris-negro conocido en muchos otros sondeos realizados en las zonas bajas de la ciudad (Dabrio y otros 2000), que se dice es el primero que integraría restos humanos mezclados con inclusiones de fauna y flora típicos de marisma, pero que a escala general de la Ría de Huelva deberá ser explicado desde otros planteamientos, si se quiere que esa situación sea aceptada como posible.

Ese color gris-negro, que también puede parecer azulado y con olor fétido, así como los restos de actividad humana, indican que su estructura sedimentaria debe ser inscrita en un proceso correlativo de formación de suelo en condiciones de encharcamiento, un suelo de carácter hidromorfo porque siempre estuvo sujeto a la actividad mareal, en el que se mezclaron, con una incidencia sometida a diferentes escalas y procesos, la erosión de materiales heterogéneos de desecho en el reborde de la marisma con la zona ya consolidada donde se localizaba el margen meridional de la población pre y protohistórica. Con posterioridad, esos restos se movilizaron por diferentes razones, tanto naturales como antrópicas, y se cimentaron definitivamente superponiéndose gradualmente en estratos más o menos amplios y homogéneos, que quizás no puedan ser diferenciados a simple vista, para quedar ocultos o ser tapizados definitivamente por otros sedimentos posteriores.
Hay que suponer que ese estrato negro representa la primera muestra de actividad humana en la marisma holocena, la cual comenzaría hace unos 6,000 años, después de concluir el episodio conocido como Máximo Transgresivo Flandriense, que como hemos dicho representa la más alta subida de las aguas del mar por el calentamiento global que se mencionó anteriormente, y que a nuestro juicio debe interpretarse como el resultado de los inicios de la progradación y acreción hacia el sur de la superficie situada al pie de los cabezos (Zazo y otros 1994), debido a la morfología natural influenciada cada vez más por la presencia humana.

Hace unos tres mil años, cuando ya parece existía en los cabezos y en las zonas llanas una población relevante, la alternancia en vertical y horizontal de las mareas, que antes y ahora representan un rango medio de 2'69 m (Morales y otros 1997: 151), quedaría reflejada en una amplia superficie cubierta de flora mareal y con abundante fauna de más de un centenar de metros de anchura, la cual podía estar atravesada por esteros y pequeños canales mareales, blanda y resbaladiza, sobre la que siempre se han dejado varadas las embarcaciones de menor porte al descender el agua durante las bajamares, una situación bastante bien conocida a través de fotografías antiguas de la Huelva contemporánea. Se trata, pues, de una superficie donde, en cualquier momento histórico, fue prácticamente imposible la implantación de viviendas sólidas con cimientos, talleres, almacenes, o cualquier estructura ocupacional no palafítica, debido a que dos veces al día, por la normal alternancia de las mareas, esta superficie era cubierta de agua en las crecientes de las pleamares y también quedaba al aire en las bajamares. No obstante, localmente, sólo pudo ser ocupada de forma efectiva cuando finalmente fue cubierta por una capa de sedimento procedente de zonas más altas lo suficiente amplia, gruesa y compacta para que su extensión superficial fuera estable, pero sólo una vez que por su nueva cota, en relación con la superficie media anual del agua, quedaba ésta apartada de la subida en las mareas con mayor coeficiente, con lo que hay que contar para ello con el tiempo de crecimiento, acreción y compactación suficientes. Aunque las medidas hayan sido tomadas en la actualidad, existen datos importantes acerca de valores de la erosión/acreción de las áreas marismeñas en la ría de Huelva, que podrían servir aquí para entender la movilidad de esas áreas también en la Antigüedad (Castellanos y otros 1997).

En síntesis, a lo largo de la evolución natural del paisaje mareal del puerto, grandes abanicos de erosión procedentes de los cabezos acrecentaron paulatinamente la orilla de la playa/marisma y diferentes formas de arroyada rellenaron los esteros subsiguientes 
(Figura 3) que, de forma progresiva, hicieron retroceder las zonas que eran inundadas diariamente hacia el sur, recreándose así nuevas situaciones cada día, una morfología siempre auspiciada e impulsada por la acción humana que la ha favorecido para ganar terreno a las aguas hacia el sur, en especial entre los últimas décadas del siglo XIX y las primeras del XX. Con el tiempo, esa orilla de la marisma fue migrando hacia el sur hasta que, en 1932, la autoridad portuaria determinó la construcción del Muelle de Levante (Chapela 1999: 110-111), denominado entonces Muelle Definitivo.

Así, en el lugar ocupado ahora por el entorno de la Plaza de las Monjas, auspiciado por el resultado de la evolución natural y de la ocupación humana de la zona, en el extremo sur del eje formado por Plaza de San PedroCalle de la Fuente-Plaza de la Palmera-Calle de las Agustinas-Plaza de las Monjas-Calle Vázquez López, fue progresando un abanico de arroyada que con el tiempo se configuró como un puntal adentrado en la marisma, y, paralelamente, por su lado occidental debido precisamente a su progradación, debió mantenerse un estero navegable que pudo ser utilizado como puerto natural, pero que siempre estuvo sujeto a las variaciones mareales, un modelo muy útil para la navegación a remo y vela.

El hallazgo de materiales antiguos en ese estrato negro y en esa zona específicamente (González y otros 2004), que sin dudas puede ser relacionado con la orilla del puerto protohistórico de esos momentos, al no presentar graves daños debido a arrastres prolongados, a menos que fuesen arrojados al agua desde los barcos fondeados o varados en ese espacio, indica que cada uno de ellos llegó a su posición postdeposicional como resultado de dispares procesos correlativos con la morfología natural y antrópica que reconocemos en el sitio arqueológico de Huelva, y de ahí que en conjunto no representen una homogeneidad cronológica que sea inferior a una o dos generaciones. De esa forma la amplitud en el tiempo que pueda estimarse entre los fragmentos cerámicos y otros objetos publicados, pudiera estar en relación con que fuesen depositados en el fango desde los barcos varados o desde la zona ocupada más cercana a la orilla, cuando esa unidad gris-negra, tal vez con superficie más oxidada y por ello con color marrón-negro, estuviese ya conformada a lo largo de décadas o siglos, incluyendo claro está materiales arqueológicos de diversa cronología, como resultado de la ocupación de la zona. En cualquier caso, algunos de esos materiales arqueológicos publicados aparecen con un color virado de sus superficies, especialmente los cerámicos, que se han degradado por permanecer en las aguas desde que fueron desdeñados por rotura (González y otros 2004; 2006: Fig. 8, 3), aunque es posible que todas las superficies de las cerámicas que ahora aparecen de color gris no estuviesen recubiertas de engobe rojo bruñido, a juzgar por paralelos de la Fine Ware tiria documentados en otros yacimientos de la costa siro-palestina (Herrera y Gómez 2004: Lám. VIII, 67; Lám. IX, 78).

Posteriormente, a partir del siglo VIII a.C., inmerso en la evolución hacia el sur de la zona comprendida entre el reborde de los cabezos y la orilla mareal, el estrato negro sería recubierto progresivamente por sedimentos procedentes del reborde de la marisma estable, donde ya aparecen las primeras huellas de construcciones pétreas permanentes (Fernández y García 2001; Osuna y otros 2001). La problemática del color de la decoración y de las pastas cerámicas, así como el hecho de que los materiales orgánicos recuperados tales como madera cortada perfectamente conservada y restos macro-vegetales, indican que las condiciones anaerobias del lugar donde se depositaron esos materiales orgánicos impedían su inmediata desaparición bien por putrefacción antes de ser cubiertos por nuevos sedimentos, bien por su recogida para ser utilizado como leña menuda en cualquiera de las normales actividades de una población marinera. Pero, sin lugar a dudas, fueron el resultado de su deposición en la llanura mareal que inundaban las crecientes, o allí fueron transportadas por diferentes procesos naturales y/o antrópicos. En este sentido nos parece extraño el hecho de que no se hayan podido conservar en ese estrato materiales de los III y II milenios a.C., de los que existen ejemplos en algunas zonas del yacimiento, o en su periferia más inmediata, puesto que si el estrato negro fuese el resultado de la más antigua ocupación del puerto, no sería insólita su presencia. Redundando en la presencia de la madera, resulta claro que sólo su deposición en ese contexto de agua, limo, barro y vegetación marismeños posibilitó su conservación hasta la actualidad, ya que el contacto con ese medio le impediría flotar y con ello su desplazamiento a otras zonas del puerto más alejadas. Volviendo al color virado de las cerámicas, en el caso del engobe rojo típico de las cerámicas fenicias, las localizadas en los sedimentos correspondientes al siglo VIII a.C., que también aparecieron incluidas en el nivel freático actual, no presentaban cualquier cambio en su color, por lo que el freático actual no fue responsable del virado del color en las cerámicas de la Fine Ware tiria del estrato negro. Tal vez la situación del freático actual no tiene nada que ver con la de la superficie protohistórica.

Como hemos mencionado, a partir del estrato negro, en la zona de la actual calle Méndez Núñez fueron depositándose niveles de ocupación humana que perduraron con construcciones pétreas hasta al menos los siglos V-IV a.C. y, en el devenir del tiempo, la zona quedaría 


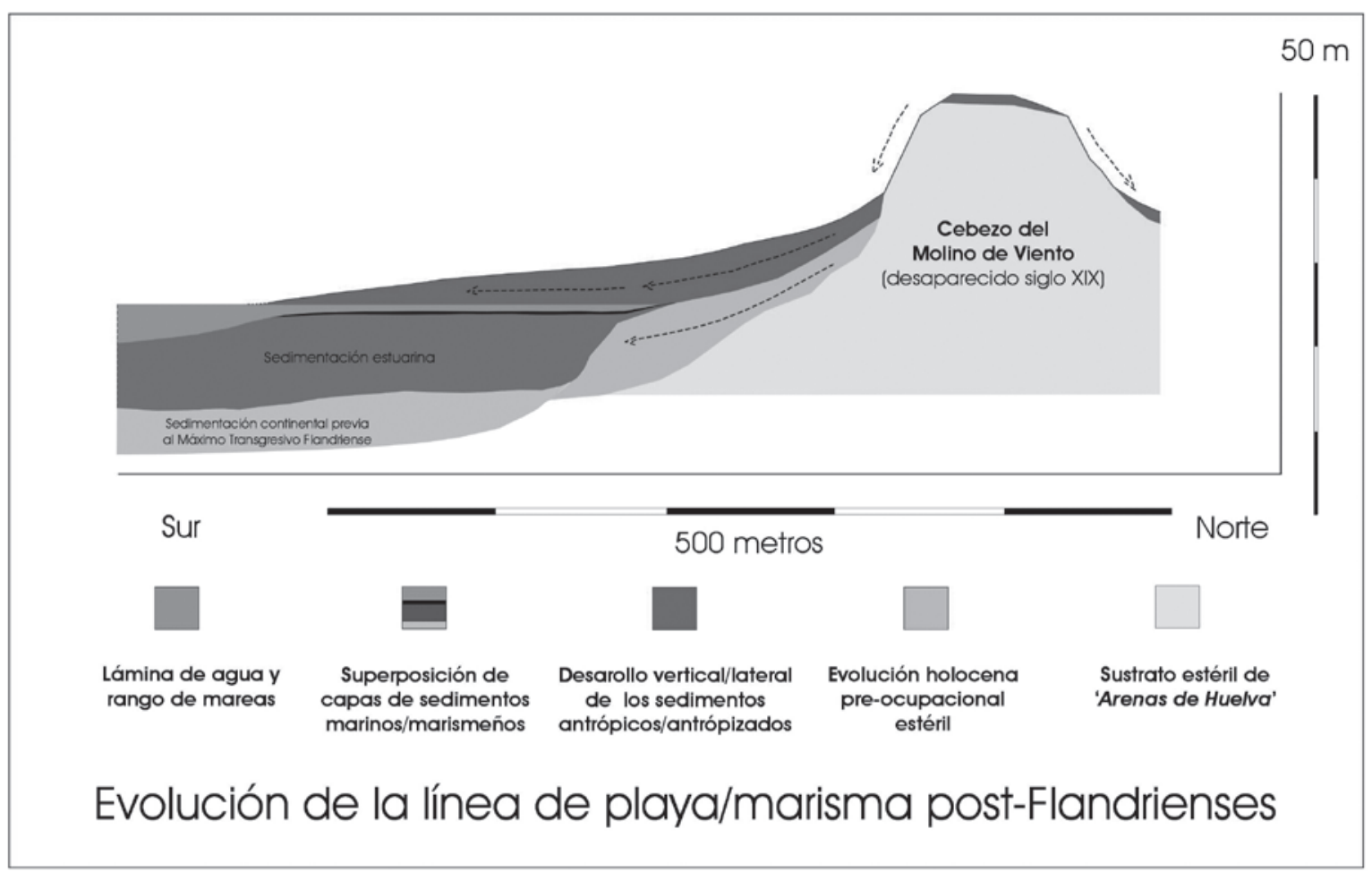

Figura 8. Interpretación de la evolución de la línea de playa/marisma postflandrienses entre los cabezos y la línea de evolución mareal.

libre de ocupación con edificios de cualquier tipo hasta la Edad Moderna, cuando la villa de nuevo amplió su extensión por las zonas llanas. Esta situación entre las zonas bajas junto a la marisma, que implica la acreción de sedimentos por procesos naturales y antrópicos, la hemos reproducido como ejemplo en la Figura 8. De cualquier forma, nuestra interpretación históricoarqueológica del hallazgo en su conjunto (González y otros 2004), la hemos incluido en el contexto del Suroeste peninsular, para el cual éste sin duda será de una importancia extrema para conocer la génesis de la sociedad local y la hasta ahora más antigua presencia de los fenicios en Occidente (Ruiz Mata y Gómez e.p.).

\section{EVOLUCIÓN MORFOLÓGICA DE LA CIUDAD DESDE UNA INTERPRETACIÓN GEOARQUEOLÓGICA.}

En el contexto de una síntesis arqueológica general de la ocupación espacial de la ciudad de Huelva, que puede contrastarse con la que uno de nosotros publicó en colaboración hace tan sólo unos años (Gómez y Campos 2001), pero comprobada en varias excavaciones realizadas recientemente al sur de la Plaza de las Monjas por debajo de edificios posteriores al siglo XV de la Era (Rastrojo y otros 2001), por ser el momento de expansión de la ciudad moderna fuera de los cabezos, en la zona más meridional no quedan restos de la Huelva medieval islámica, lo cual indica que ésta se limitó a ocupar las áreas más altas del barrio de San Pedro (Gómez y otros 2003). De la misma forma, la Onuba romana, a excepción de alguna necrópolis localizada en el extremo sur del puntal que hemos mencionado, se extendía por el eje donde ahora se extiende la calle Vázquez López (Figura 1), y pocos son los restos conocidos por debajo de la cota actual existente al sur del eje Plaza de las Monjas-Calle Méndez Núñez-Placeta, con lo que también la ciudad romana debió extenderse al nordeste de dicho eje, ocupando fundamentalmente los cabezos de San Pedro y los hoy perdidos del Cementerio Viejo y del Molino de Viento (Figura 2) y una zona baja limitada por esa cota y la Plaza de San Pedro (Figura 1).

Para la ciudad prerromana anterior al siglo IV a.C., las excavaciones realizadas en las últimas décadas 
muestran un modelo mucho más complicado. La zona más antigua con influencia humana corresponde al estrato negro que hemos mencionado en el capítulo anterior, que se formó a partir de la evolución holocena de la línea de playa-marisma inundada por las mareas a partir del Máximo Transgresivo Flandriense hace 6,000 años, y de la ocupación humana de la zona que debió quedar allí representada, donde hemos dicho deberían incluirse también materiales arqueológicos anteriores al Período Protohistórico. De acuerdo con la cronología que presentan los materiales más recientes documentados por encima de ese estrato negro, en la segunda mitad del siglo VIII a.C. comenzaron a construirse los primeros muros de barro y piedra del hábitat protohistórico en una superficie que ya no sería afectada por las crecientes (Osuna y otros 2001), avanzando gradualmente hacia el sur los primeros almacenes y la infraestructura portuaria de la ciudad del Período Orientalizante de los siglos VIII-V, en un proceso que se mantendría, con una incidencia diversa en relación con la capacidad técnica del momento, hasta los inicios del siglo XX tras la construcción del Muelle de Levante, que como sabemos había incorporado como relleno antrópico el desmonte manual de los cabezos del Molino de Viento y del Cementerio Viejo (Sugráñes 1995; Gómez y Campos 2001).

Desde los presupuestos contemplados en esta interpretación que pretende ser no sólo una descripción de la posible evolución de una parte del asentamiento arqueológico, la más cercana a la marisma en los primeros siglos del I Milenio a.C., podrían ser analizados otra vez muchos de los cortes estratigráficos realizados en las zonas llanas más meridionales, y dar lugar a una más justa explicación planimétrica de la evolución de la ciudad. Aquí, años después, nos parece interesante resaltar por su claridad, que en una de las actuaciones realizadas en las zonas bajas, en la calle San Salvador, pudo documentarse lo que en esos momentos nos pareció ser la playa holocena al estar conformada por arenas limpias, la cual encontramos prácticamente libre de materiales arqueológicos (Gómez y otros 2002), y donde casualmente no documentamos el nivel gris-negro al que reiteradamente no hemos referido más arriba, como importante indicador de la evolución morfológica de este espacio situado posiblemente en la esquina sudoeste del yacimiento, tal vez porque en esa zona también existió un puntal que se adentraba en la marisma, como resultado de la progradación hacia el sur de uno de los principales abanicos de arroyada observados en el yacimiento (Figura 3). También, esperamos que sirva como una reflexión meditada, que podrá ser matizada en futuros trabajos, pero que nos parece imprescindible a la hora de establecer cronologías históricas, o fundamentar una sincronía específica, a conjuntos de materiales no excavados con uno de los métodos al uso donde pueda establecerse una identidad geoarqueológica y un proceso concreto que diese lugar a su sedimentación.

Sin embargo, como premisa general, dado el método simplista generalizado con que anteriormente se explicaban las estratigrafías, la sucesión en el tiempo de materiales arqueológicos, tanto restos mueble como inmuebles mejor o peor conservados, ha servido para establecer la evolución en el espacio de la cultura material existente y, de ahí, su consideración e interpretación histórica. Pero, como algunos ejemplos son realmente muy expresivos, no podemos evitar un comentario que debemos achacar a la profesión en general y a la evolución que afortunadamente sufren los métodos arqueológicos a través del tiempo, y nunca como una crítica a los que con mayor o menor fortuna nos precedieron o a los que ya la investigación del sitio arqueológico de Huelva no significa un lugar preferente de su actividad profesional.

Entre los datos suministrados por los trabajos realizados a finales de los años ochenta, una actuación específica, que tal vez deba estimarse como uno de los paradigmas de la década de los noventa, nos servirá para recordar tanto la existencia de los procesos postdeposicionales como su influencia en la interpretación histórica que ahora manejamos, que por necesidades de brevedad no hemos incluido en el apartado anterior. La estratigrafía del solar número 9 de la calle del Puerto, tal como se explicó en su día (Fernández 1990: 142171), muestra unas características específicas tan claras que significa un ejemplo a tener en cuenta para otras muchas áreas del sitio arqueológico de Huelva (Fernández 1990: Figs. 31-32). En ella se muestran diferentes estratos superpuestos (Estratos 6-10) que fueron cortados por otros diferentes más recientes (Estrato 7), los cuales indican la excavación o destrucción natural de la superficie de los primeros ya conformados como un conjunto homogéneo previo, la cual fue cubierta por otros estratos diferenciados en un momento posterior. Como no se aprecian en ese contexto elementos constructivos de cualquier tipo, que pudiesen estar separados por esos paquetes sedimentarios, a través del análisis de los elementos de cultura material localizados debió establecerse un tiempo relativamente amplio para su conformación, puesto que los rellenos contenían cerámicas sincrónicas y diacrónicas que invalidan la interpretación de superposición estratigráfica simple estimada, pues no se trataba de una deposición en la que esos estratos se superpusieran a lo largo de un 
tiempo corto, sino que tal vez se debiera al arrastre de materiales que ya se encontraban en situación postdeposicional en el lugar de partida, por supuesto en cotas superiores. En cualquier caso, desde la interpretación geológica de las estratigrafías arqueológicas, que era el método generalmente utilizado, se habla de inundación para explicar la génesis de los paquetes sedimentarios que cortaban en su arrastre a los otros en disposición horizontal, sin duda un intento positivo de mostrar una conformación diferente de la exclusivamente antrópica que prácticamente era la usual en aquellos años de inicios de la década de los noventa, indicando, incluso, que ...los materiales arrastrados ...se disponían según su granulometría (Fernández 1990: 149), por lo que la grano-selección de los materiales observada, con cerámicas y gravas más pesados debajo y arena prácticamente limpia en las zonas altas, indica claramente la culminación de un proceso de arroyadas naturales debido a la circulación del agua de lluvia superficial ${ }^{3}$. Sin embargo, a la hora de establecer la secuencia histórico-arqueológica, los materiales arqueológicos, especialmente los griegos arcaicos, fueron estudiados y explicados en función de su morfología y tipología arqueológica, tal como éstos eran conocidos a partir de su estudio en las diferentes ciudades de la Grecia Arcaica y en las colonias mediterráneas (Cabrera 1990), y no de acuerdo con su superposición estratigráfica. De hecho, como ejemplo, en el Nivel 1 más profundo apareció un fragmento de copa ática del tipo de Comastas (Fernández 1990: Lám. LVII, 6), similar a otro localizado en el Nivel III, que es inmediatamente anterior al proceso de arroyada que erosionó la superficie de los mencionados, también atribuido a copas de mismo tipo y cronología (Fernández 1990: Lám. CVIII, 15-16).

La existencia al mismo tiempo de cerámicas del Bronce Final y platos fenicios de engobe rojo de borde estrecho a lo largo de los estratos estudiados indica, sin lugar a dudas, que toda la estratigrafía analizada responde a un modelo de arrastre y deposición natural del tipo generalizado que en Arqueología denominamos postdeposicional, cuya cronología, y no la de cada uno de los fragmentos cerámicos incluidos, debe ser posterior al fragmento cerámico más moderno localizado en el mismo conjunto.

3. En regímenes de pluviometría incluso moderada, la escorrentía superficial desplazaba por gravedad materiales de diverso volumen y peso. Al cesar la lluvia o a medida que perdía su competencia el caudal de agua que circulaba, los elementos más pesados quedarían depositados en primer lugar mientras que las fracciones de grava, arena y arcilla se superpondrían unas a las otras en función de su peso específico, es decir por grano-selección, desde la fracción más gruesa a la más fina.

\section{LA NECESIDAD DE UN NUEVO MODELO DE EXPLICACIÓN HISTÓRICA}

Desde la experiencia adquirida en las excavaciones de la ciudad de Huelva, debe entenderse la necesidad de revisar trabajos que a lo largo de las últimas décadas han servido para fundamentar la evolución histórica de la ciudad. Como hemos comentado, no debe interpretarse que con este trabajo pretendamos culpar de cualquier deficiencia o incapacidad a los profesionales que llevaron a cabo las excavaciones en momentos anteriores a la generación actual. Tan sólo la experiencia previa y el estudio que realizamos de diversas excavaciones actuales nos han hecho recapacitar acerca de la eficacia de nuestros métodos y de los que estaban vigentes en décadas anteriores.

Desde este planteamiento, queda suficientemente claro que trabajar con los resultados publicados hasta ahora, correspondientes a trabajos de campo realizados hace varias décadas con los métodos entonces vigentes no será bastante para alcanzar la coherencia científica necesaria a la hora de poner por escrito nuestras interpretaciones histórico-arqueológicas deducidas de los trabajos de campo y de la historiografía existente. Es evidente que las estratigrafías publicadas hasta ahora, sin su revisión o puesta al día, no pueden ser un referente digno de credibilidad, o al menos ésta ha de mantenerse en reserva. La superposición de elementos arqueológicos que han dado lugar a las tipologías de artefactos con que ahora establecemos el tiempo histórico no son suficientes. En realidad, esas tipologías han sido, no puede olvidarse, la interpretación objetiva del resultado de la investigación de diferentes autores y no una evidencia empírica por sí, puesto que ese resultado siempre ha de considerarse, al menos, una hipótesis de trabajo que con el tiempo deberá ser contrastada por los que nos sucedan.

De cualquier manera, entendemos que la interpretación futura de cualquier actuación arqueológica que quiera explicarse e interpretarse históricamente, para ser coherentes con el registro arqueológico documentado, deberá incorporar el análisis físico de las diferentes unidades estratigráficas existentes en un sitio dado, intentando conocer su posible génesis y conformación en relación con la interrelación de los procesos naturales con la ocupación humana, lo cual debe contribuir decisivamente a una necesaria credibilidad científica que ya no podrá eludirse. No bastará, por tanto, el estudio de cada uno de los fragmentos susceptibles de aportar una tipología y una atribución histórico-arqueológica específica, especialmente si a ella se llega a través de paralelos observados en las excavaciones 
arqueológicas realizadas e interpretadas con métodos que si eran considerados los más científicos y los más adecuados en su momento, para ser coherentes y no utilizar indiscriminadamente el término obsoleto, parece lógico que se utilicen los métodos ahora conocidos o validados a escala general, con el riesgo de que nuestra penitencia sea recibir críticas justificadas en un pronto futuro, cuando otros métodos lleguen a implementarse para invalidar a los nuestros, que ya habrán adquirido también la calidad de obsoletos. En cualquier caso, sí nos parece grave reiterar interpretaciones que fueron establecidas en pasadas décadas con los métodos entonces considerados científicos, y que no se contemple, sin la crítica pertinente, las novedades publicadas por otros investigadores en momentos más recientes, de lo cual se infiere que esa será una tarea equivocada sin la menor trascendencia para el futuro de la investigación.

\section{BIBLIOGRAFÍA:}

AMO, M. del y BELÉN, M. (1981): "Estudio de un corte estratigráfico en el Cabezo de San Pedro", Huelva Arqueológica V: 57-148. Madrid.

BELÉN, M.; FERNÁNDEZ-MIRANDA, M. y GARRIDO, J.P. (1978): "Los orígenes de Huelva. Excavaciones en los Cabezos de San Pedro y La Esperanza", Huelva Arqueológica III. Madrid.

BLÁQUEZ, J.M.; LUZÓN, J.M.; GÓMEZ, F. y CLAUSS, K. (1970): Huelva Arqueológica. Las cerámicas del Cabezo de San Pedro, Huelva. Huelva.

BLÁZQUEZ, J.M.; RUIZ MATA, D.; MARTÍN DE LA CRUZ, J.C.; REMESAL, J.; RAMÍREZ, J.L. y CLAUSS, K. (1979): “Excavaciones en el Cabezo de San Pedro (Huelva). Campaña de 1977”, Excavaciones Arqueológicas en España, 102. Madrid.

BUTZER, K. W. (1982): Geoarqueología. Una ecología del hombre: Método y teoría para un enfoque contextual. Barcelona.

CABRERA BONET, P. (1990): "El comercio foceo en Huelva: Cronología y fisonomía", Huelva Arqueológica X-XI, 3: 41-100. Huelva.

CAMPOS CARRASCO, J.M. y GÓMEZ TOSCANO, F. (1997): "La ocupación humana entre los tramos bajos del Guadiana y el Guadalquivir. Su incidencia en la evolución de la costa holocena", en J. Rodríguez Vidal (ed.), Cuaternario Ibérico: 305-313. Huelva.

CASTELLANOS, E.M.; LUQUE, C.J. y FIGUEROA, M.E. (1997): "Modelo anual de la dinámica de sedimentos en la marisma mareal del Odiel (Huelva)", en J. Rodríguez Vidal (ed.), Cuaternario Ibérico: 149-150. Huelva.

CHAPELA CABRERA, P. (1999): "Los muelles proclaman la realidad del puerto (1873-1960)", en J. Monteagudo (dir.), El Puerto de Huelva. Historia y Territorio: 97-112. Huelva.

DABRIO, C.J.; ZAZO, C.; GOY, J.L.; SIERRO, F.J.; BORJA, F.; LARIO, J.; GONZÁLEZ, J.A. y FLORES, J.A. (2000): "Deposicional history of estuarine infill during the last postglacial transgression (Gulf of Cadiz, Southern Spain)", Marine Geology 162: 381-404.

DÍAZ ZAMORANO, M.A. (1999): Huelva. La Construcción de una Ciudad. Huelva.

FERNÁNDEZ, J. y GARCÍA, C. (2001): "Excavación arqueológica en el solar 7-13 de la calle Méndez Núñez y 12 de la Plaza de las Monjas", Anuario Arqueológico de Andalucía (AAA'1997), III: 336-339. Sevilla.

GARRIDO, J.P. (1968): "Excavaciones en Huelva. El Cabezo de La Esperanza", Excavaciones Arqueológicas en España 63. Madrid.

GARRIDO, J. P. y ORTA, M. E. (1970): “Excavaciones en la necrópolis de la Joya ( $1^{\mathrm{a}}$ y $2^{\mathrm{a}}$ campañas)", Excavaciones Arqueológicas en España 71. Madrid.

- (1978): "Excavaciones en la necrópolis de la Joya, Huelva II. (3 $3^{\mathrm{a}}, 4^{\mathrm{a}}$ y $5^{\mathrm{a}}$ Campañas)", Excavaciones Arqueológicas en España 71. Madrid.

GÓMEZ, F. (en prensa): “Cerámicas del Bronce Final en Huelva (1200-600 a.C.). Nueva Tipología para explicar su amplitud cronológica", en Homenaje a la Dra. Pilar Acosta. Tabona. Sta. Cruz de Tenerife. GÓMEZ, F. y CAMPOS, J.M. (2001): Arqueología en la Ciudad de Huelva (1966-2000). Servicio de Publicaciones. Universidad de Huelva. Huelva.

- (en prensa): "El Bronce Final Prefenicio en Huelva según el registro arqueológico de la ladera noroeste del Cabezo de San Pedro. Una revisión cuarenta años después", Complutum 8. Madrid.

GÓMEZ, F.; LÓPEZ, M.A. y HARO, J. (2002): “Arqueología Urbana en Huelva. El solar de calle San Salvador 2", Anuario Arqueológico de Andalucía (AAA'99), III: 315-319. Sevilla.

GÓMEZ, F.; LÓPEZ, M.A. y BELTRÁN, J.M. (2003): "Nuevas perspectivas históricas acerca de la Huelva islámica", Huelva en su Historia 10: 29-51. Servicio de Publicaciones de la Universidad de Huelva. Huelva.

GONZÁLEZ DE CANALES, F.; SERRANO, L. y LLOMPART, J. (2004): El emporio fenicio precolonial de Huelva (ca. 900-770 a.C.). Biblioteca Nueva, Madrid. 
- (2006): "The Pre-colonial Phoenician Emporium of Huelva ca 900-770 BC", BABesch (Annual Papers on Mediterranean Archaeology) 81: 13-29. Leiden.

HARRIS, E.C. (1989): Principles of Archaeological Stratigrafy. Londres (Ed. Esp. Barcelona, 1991).

HERRERA, M.D. y GÓMEZ, F. (2004): Tell Abu Hawam (Haifa, Israel). El horizonte fenicio del Stratum III británico. Huelva.

MORALES, J.A.; PENDÓN, J.G.; BORREGO, J.; JIMÉNEZ, I. y LÓPEZ, M.(1997): "Modelo de circulación mareal en la desembocadura del río Tinto (Huelva)"; en J. Rodríguez Vidal (ed.), Cuaternario Ibérico: 151-153.

OJEDA ZÚJAR, J. (1989): "La dinámica litoral reciente de la costa occidental de Andalucía", El Cuaternario en Andalucía Occidental. AEQUA Monografias 1: 123-132. Sevilla.

OSUNA, M.; BEDIA, J. y DOMÍNGUEZ, A.M. (2000): "El santuario protohistórico hallado en la calle Méndez Núñez (Huelva)", en P. Cabrera y $\mathrm{M}$. Santos (coord), Ceràmiques jònies d'època arcaica: centres de producció $i$ comercialització al Mediterrani occidental: 177-188. Barcelona.

RASTROJO, J.; MEDINA, N.; CASTILlA, E.; HARO, J. de y LÓPEZ, M.A. (2004): “Intervención arqueológica de urgencia en el solar $\mathrm{n}^{\circ} 2$ de la Plaza de las Monjas (Huelva)", Anuario Arqueológico de Andalucía (AAA'01), III: 542-544. Sevilla.
RODRÍGUEZ VIDAL, J.; RODRÍGUEZ RAMÍREZ, A.; CÁCERES. L.M.; CLEMENTE, L.; GUERRERO, V.; CANTANO, M.; BELLUOMINI, G. e IMPROTA, S. (1997): "Evolución holocena de las formaciones litorales de la costa de Huelva", en J. Rodríguez Vidal (ed.), Cuaternario Ibérico: 77-83. Huelva.

RUIZ MATA, D.; BLÁZQUEZ, J.M. y MARTÍN DE LA CRUZ, J.C. (1981): "Excavaciones en el Cabezo de San Pedro (Huelva). Campaña de 1978", Huelva Arqueológica V: 149-316. Madrid.

RUIZ MATA, D, y GÓMEZ TOSCANO, F. (en prensa): "El final de la Edad del Bronce en el Suroeste Ibérico y los inicios de la colonización fenicia en Occidente", en S. Celestino, N. Rafel, y X.L. Armada (eds.), Contacto cultural entre el Mediterráneo y el Atlántico (siglos XII-VIII ANE). La precolonización a debate. Escuela Española de Historia y Arqueología de Roma, CSIC.

SUGRÁÑES GÓMEZ, E.J. (1995): El Muro y Escalinatas de San Pedro de Huelva. Huelva.

ZAZO, C.; GOY, J.L.; GUILLAIRE, M.; DABRIO, C.J.; HOYOS, M.; LARIO, J.; BARDAJÍ, T.; SOMOZA, L. y SILVA, P.G. (1994): "Variaciones del nivel del mar. Estudios isotópicos 7, 5 y 1 en las costas peninsulares (S y SE) e insulares españolas", Gibraltar during the Quaternary, AEQUA Monografias 2: 26-35. Sevilla.

FECHA DE ENTRADA: 08-09-2007

FECHA DE ACEPTACIÓN: 16-09-2008 